\title{
Did we make a difference?
}

We hold stereotypes. Everybody does that. For scientists it is a little harder to demonstrate who they simply are, because often people are blind to non-stereotyped views of scientists and science. Some of the elements of the stereotypes concerning scientists, for example the fact that they are smart and hard-working, are certainly true and are in fact important characteristics of a good scientist. But being eccentric and socially isolated and living an unbalanced life are not realistic traits that can be applied to all the members of the scientific community; scientists are normal people with families, friends, hobbies.

The objective of our Light project was twofold: first, to foster an enthusiasm for the scientific process of discovery and to promote an interest in future participation in science-related careers for young people; second, to offer people with different cultural 
backgrounds the opportunity to change their stereotypical ideas of science and scientists. In order to achieve these goals, the activities were centred on the interaction between scientists and citizens: non-scientists used scientific tools, talked with real scientists, and gained scientific knowledge so that they may become informed members of their communities.

What we have done, as compared to other activities aimed at changing people's stereotypical image of scientists, presents points of strength and weaknesses. Hopefully, what we did better than anyone else was to achieve a real interaction between scientists and the public. This was achieved through a purposively designed set-up of the venue of the event, aimed at eliminating potential barriers to effective interaction between scientists and the public. The spatial context has a great impact on verbal and nonverbal communication and on the quality of interaction, although this is often overlooked. Organizers of science communication events take for granted the idea that tables, chairs, microphones, screens etc. are neutral tools, and do not perceive them as elements that create a communication barrier between the experts and the public. In a situation where people were coming to specifically interact with scientists, to be convinced to change their ideas about scientists or to be inspired by science, it was essential to do whatever we could to remove the barriers - literally and figuratively between experts and laypeople.

We had architects and event designers as our partners for the project. They understood our needs and supported the strategic decisions we took when planning activities aimed at dismantling stereotypes about scientists. From the early stages of the project, architects assessed the venue, set out options, carried out feasibility studies and helped us to develop the project brief into strategic activities. 
A good example of this is the glass ceiling sensorial experience described in Chapter 2, which is an effective tool to make people aware of the existence of gender stereotypes in science. We set up the glass ceiling experience in different contexts, for example in one of Rome's biggest shopping centre or next to a modern art museum. These sites did not have any connection with science, so the people passing by did not expect to be confronted with the scientific world: it was amazing to see people queuing to go through the glass ceiling experience, asking questions after having gone through it and showing a clear interest about the situation of female scientists.

We also made efforts to eliminate the language barriers between scientists and ordinary people. We know that the words we choose, how we use them and the meaning we attach to them cause many communication barriers. Furthermore, if people do not understand the words, they cannot understand the message. That is the reason why we strongly recommend to brief scientists who participate in science communication events. We did it, and had very good results in improving the communication skills of scientists.

A further strength of our events to favour the change of people's stereotypical image of scientists was the possibility for the public to see what scientists do when they do not do science through the Globe Science Theatre activity, where scientists performed their hobbies, dancing, playing or doing sport. This was a crucial aspect to show the human side of scientists and to break down psychological barriers between scientists and ordinary people.

To realize all these activities we had the advantage of having unique, low-cost resources at our disposal that others cannot easily obtain: CNR researchers participated at no cost and came from all over the country, the CNR press office was extremely helpful 
and effective in contacting the media and we had access for free to very costly equipment and to low-cost venues. Last but not least, we had funds from the European Commission.

We are conscious that nothing is perfect and that there are aspects of our activity that should be improved. A weak point of Light's impact assessment was the absence of follow-up data to evaluate the long-term outcomes on people's opinions on scientists. It may be possible to alter negative attitudes towards scientists and science by giving people accurate information and the possibility of interacting with scientists, but the change may be short-lived. If you want to repeat our experience, we suggest you plan a follow-up survey. For us this was impossible due to the extremely high number of participants and the limited budget. However, it was possible to follow-up the younger participants of the INV-Factor competition: more than 70 per cent of the young inventors decided to choose a STEM education - and will hopefully choose a STEM job.

New opportunities are coming to the fore in Europe. As mentioned in the introduction, the European Union has launched a seven-year RRI (Responsible Research and Innovation) strategy. RRI is largely based on "public engagement", which essentially means the involvement of a diversity of stakeholders - representing research, industry, and policy and public bodies, including civil society organizations - and citizens in general. There are plenty of benefits in involving the broadest possible range of actors in innovation and research, but it is essential to remove bias and stereotypes that make the dialogue and interaction between experts and non-experts difficult, if not impossible. Thus, initiatives and actions aimed at removing stereotypes about scientists can be of great help.

Moreover, we live in a period of changes in social patterns, population profiles and lifestyles, of increasing levels of education in 
the population, increasing attention of people towards scientific progress that makes life better and an increasing interest of governments in encouraging young boys and girls to choose a scientific career. People with increased education levels, knowledge and scientific outlook are more liable to change their points of view, and their stereotypical images of scientists are more easily changed.

But did we really make a difference in changing unrealistic stereotypical images of what a scientist is and does in people's minds? Let us be entirely honest with ourselves and with our readers. Actions aimed at changing stereotypes of scientists are infrequent. When actions are implemented, stereotypes do change with time, but often they only fade and are not totally removed from people's minds. Undoubtedly mass media play an important role in the maintenance of stereotypical images of scientists, as we said in previous chapters. All this lets us conclude that although stereotypes concerning scientists grow weaker when ordinary people are exposed to actions aimed at modifying their clichéd ideas on science and scientists, they often persist. This is not a good reason for doing nothing: it is in fact a good reason to perform counter-stereotypical actions and activities concerning scientists more often. 